\title{
Effects of Prenatal Tobacco Smoke on Lungs Histo-Morphological Changes of CD-1 Mice at Embryo Developmental Stage
}

\author{
Issa S Al-Amri' ${ }^{*}$, Isam T Kadim ${ }^{1 *}$, Abdulaziz Y Alkindi ${ }^{1}$, Ahmad \\ Hamaed $^{1}$, Samera K Khalaf ${ }^{2}$, Zainab A Al-Sabti ${ }^{1}$, Reem Al-Habsi ${ }^{1}$, \\ Wameath Abdul-Majeed ${ }^{3}$, Asiya Al-Hooti ${ }^{1}$ and Asala I Al-Amri ${ }^{1}$ \\ ${ }^{1}$ Department of Biological Sciences and Chemistry, College of Arts and Sciences, \\ University of Nizwa, Birkat Al-Mouz, Nizwa, Sultanate of Oman \\ ${ }^{2}$ Natural and Medical Sciences Research Center, University of Nizwa, Birkat \\ Al-Mouz, Nizwa, Sultanate of Oman \\ ${ }^{3}$ Department of Chemical Engineering, College of Engineering, University of Nizwa, \\ Birkat Al-Mouz, Nizwa, Sultanate of Oman \\ *Corresponding Author: Issa S Al-Amri and Isam T Kadim, Department of \\ Biological Sciences and Chemistry, College of Arts and Sciences, University of Nizwa, \\ Birkat Al-Mouz, Nizwa, Sultanate of Oman.
}

Received: October 31, 2020

Published: November 12, 2020

(C) All rights are reserved by Issa $\mathbf{S} \mathbf{A l}-\mathbf{A m r i}$, Isam T Kadim., et al.

\begin{abstract}
The study was aimed to evaluate the effect of exposure of pregnant female CD-1 mice to standard cigarettes' smokes on histopathological changes of 10 days old juvenile lungs tissues at the cellular level. A total of 30 female CD- 1 mice were randomly divided into three sets of 10 mice each and placed in a special modified smoking machine over the experimental period. The first set were exposed to fresh air (control group); while the mice in the other two sets were exposed to tobacco smokes from standard filter cigarettes for 2 (group 2) and 3 (group 3) weeks, respectively. The fumes from these cigarette brands contain nicotine, tar and carbon monoxide. The mice in the exposed set groups were in contact with the fumes from 6 cigarettes for two exposure of 15 minutes per day. At the end of the experiment, mice were decapitated under deep anesthesia, and the lungs were dissected under stereomicroscope. Histological results showed that exposure of mice to tobacco smokes for three weeks caused significant histological changes in the lungs epithelium which include epithelial cells proliferation, cilia disruption as well as presence of inclusion bodies. Alveolar wall thickening, collapsed alveoli and blood extravasations were also observed. These structural changes constitute great index that nicotine induced these changes, similar to the changes observed when experiencing long term tissues irritation. This study showed that prenatal tobacco smokes had a negative effect on gaseous exchange in alveoli and predispose to neoplastic changes.
\end{abstract}

Keywords: Tobacco Smokes; Lungs; Histo-Morphological; CD-1 Mice; Embryo

\section{Introduction}

Smoking is a mechanism of nicotine delivery. Nicotine is a powerful central nervous system stimulant which provides smokers with instantaneous gratification that leads to long-term addiction [1]. Smoking is defined as the act of inhaling and exhaling fumes from burning tobacco and it can be classified into mainstream smoke that is inhaled from cigarettes during puffing and side-stream smoke or secondhand smoke that is emitted by burning cigarette between puffs [2]. In this respect, Stephen [3] stated that the side-stream smoke contains high levels of toxic and carcinogenic chemical compounds than the main-stream smoke. In particular, mainstream smoke contains cancer-causing and harmful chemical such as naphthalene, pyrene and nitrosamine. These compounds are the main constituents of the so-called tar 
[4]. Moreover, cigarettes contain over 4,000 chemical compounds including 60 known carcinogens [3]. The gaseous components of the main-stream smoke, which constitute the vast majority of the total smoke, contain about 450 different gases [5]. Tobacco smoke is also considered as a major factor to many non-cancer diseases in the respiratory system such as chronic obstructive pulmonary disease, pulmonary hypertension, and asthma. Tobacco has also many adverse effects on the respiratory health and the wellbeing of newborns. The effect of tobacco smoke on the respiratory system of rats was studied by Shraideh and Najjar [6] and showed a significant histological change in lung.

Although, the concentration of nicotine is different in each tobacco brand, in general, all tobacco contains between 8 and 9 mg of nicotine [7], which exceeds the permissible limit. Epidemiological studies showed that there is a high correlation between pulmonary, cardiovascular disease, lung cancer and the exposure to tobacco smoke [8]. Tobacco smoke exposure is more evident among the youth which is attributed to higher respiration rates. It is estimated that more than $50 \%$ of babies in the various regions of the Middle East are exposed to tobacco smoke. Poor quality control in many tobacco brands is usually associated with great health risks which jeopardize the therapeutic outcomes in Omani fetus.

\section{Aim of the Study}

The aim of the present investigation was to assess the effect of prenatal tobacco smokes on the histological structural changes in the 10 days old juvenile lungs tissues at the cellular level at basic critical developmental stages.

\section{Materials and Methods}

The most popular international tobacco cigarette brand in Oman was were purchased from the local shops and stored at room temperature $\left(22-24^{\circ} \mathrm{C}\right)$ until processing.

\section{Mice}

A sample of 30 pregnant CD-1 mice of 7 months of age and weighing between of 30 and $35 \mathrm{~g}$ were randomly split into three sets. The first set represents control group. It is comprising 10 pregnant female mice which are exposed to the ambient filtered room air for two periods of one hour each daily for 14 days. The second and third set represent the tobacco smoke groups, comprising 10 mice each. The mice in these two sets are exposed to tobacco from three different brands of cigarette for two periods of one hour each on a daily basis for two and three weeks, respec- tively. The smoking device was set to cycle with cigarette suction periods of 10 seconds and rest periods of 15 seconds, followed by a 5-minute rest period during which fresh air from the room was delivered to prevent hypoxia. The mice in set two and three were exposed to a mixture of $15 \%$ main stream smoke which is pumped through filter and $85 \%$ side stream smoke that is diluted with air to a concentration of $3 \mathrm{mg} / \mathrm{m}^{3}$ of repairable suspended particulate. During each exposure, cigarettes were consumed at a rate of one puff per minute, two second per puff of $35 \mathrm{~cm}^{3}$, for eight puffs in nine minutes per each cigarette. This model provided comparable airborne exposure as experienced in a $50-\mathrm{m}^{3}$ household room of 0.7 air changes per hour, with a smoker consuming 2 cigarettes per hour over a 10 -hour period, which was validated by repeated mass measurements of repairable suspended particles.

The apparatus consists of two parts: A mice containment compartment and a cigarette smoking device. The mice containment compartment comprises 3 cages of $24 \mathrm{~cm}, 17 \mathrm{~cm}$ and $15 \mathrm{~cm}$ dimensions closed at the top. The 3 apparatuses were placed equidistant from each other: 2 for the mice in the cigarette smoke groups 2 and 3 , while the $3^{\text {rd }}$ apparatus was used for group 1 . The cigarette smoke delivery system consists of an external cigarette holder connected to a dynamic suction pump by a flexible hose. The pump can be programmed to alternate between periods of cigarette suction and periods of clean air suction, to prevent asphyxia. The pump generates negative pressure, which forces the air through a lit-up cigarette, generating cigarette smoke and pushing it toward the hose and into the acrylic box. The local design features of the currently in use apparatus are similar to those of commercially available systems used by many researchers $[9,10]$. In the current design features, mice were exposed to fumes via whole-body exposure because the smoke was pumped into the exposure chamber and generated by the puffing of three cigarettes in good mimicking of the actual smoking. The used apparatus permits the regulation of the suction power; the suction time is adjusted by means of a timer. The main advantages of the currently in use apparatus are its low cost, its simple design and its ease of installation.

\section{Histology}

After twenty-four hours of smoke exposure, mice were decapitated under deep anesthesia of $5 \%$ isoflurane for five minutes. Both lungs were dissected using stereomicroscope and examined with the naked eye for gross abnormal changes then immersed in $10 \%$ formaldehyde solution until section preparation. Tissue prepara- 
tions were accomplished by using the Automated Tissue Processer instrument (ATP 140). In this process tissues were dehydrated by graded concentrations of ethanol 70\%, 90\%, 1 h each and 3 changes of $100 \%$ ethanol for 1,2 and $2 \frac{1}{2} \mathrm{~h}$ respectively. Tissues were then cleared with 3 changes of xylene for $(1,1,2 \mathrm{~h})$ respectively, then infiltrated in 3 changes of melted paraffin wax at $60^{\circ} \mathrm{C}$ for $1 \mathrm{~h}$ each. Samples were then embedded in pure paraffin wax by using the Embedding Center Machine (AEC 380). Paraffin blocks were sectioned by Rotary Microtome (AEM 450) to produce thin sections of $5 \mu \mathrm{m}$ thickness, 3 slides being therefore prepared for each block. Sections were collected with glass slides and placed on hot plate. Sections were then placed in xylene for 2 periods of 5 minutes each to remove wax, then hydrated in 2 changes of pure ethanol of 5 minutes each, then in 95\% ethanol and then in 70\% ethanol for 2 minutes each, then in distilled water for 2 minutes. Each section stained with Hematoxylin and Eosin ( $\mathrm{H}$ and $\mathrm{E}$ ), dehydrated with $95 \%$ ethanol for 3 to 5 dips, 2 changes of $100 \%$ ethanol for 2 minutes each, and then cleared with xylene for 5 minutes each. Finally, slides were mounted with DPX and cover slip and screened under light microscope. Ten randomly selected non-overlapping fields were investigated by histologists under light microscopy for each slide at different magnification.

\section{Results}

Digital light microscopic observation of lung sections showed remarkable difference among groups 1, 2 and 3. Control group (1) showed normal lung morphology with uniform alveoli and bronchioles as shown in figure 1A-1C. Group 3 showed significant changes in the lung morphology with thickening of alveolar wall, and infiltration of inflammatory cells as shown in figure 3A-3D. The mice in the control group sections showed normal lung tissue made up of bronchioles, alveolar ducts and alveoli, and blood vessels (Figure 1A-1D). In the lung, each bronchus splits into narrower bronchi that terminate in bronchioles (Figure 1A). The alveoli composed of a single layer of squamous epithelium surrounding alveolar sac (Figure 1B). Between the alveoli a thin layer of connective tissue and numerous capillaries are lined with simple squamous epithelium. The alveoli are composed of two morphologically distinct cells of type I and type II pneumocytes alveolar cells as shown in figure $1 \mathrm{C}$.

In group 2, tissues from the lung exhibited no change in the morphology after one-week exposure to tobacco smoke (Figure
2A-2D). The bronchiole's wall consists of ciliated cuboidal and a thin layer of smooth muscle (Figure 2B). The number of goblet and ciliated cells decreases as getting closer to the terminal bronchioles, whereas that of Clara cells increases proportionally. The pulmonary lobule, which is also known as the acinus or terminal respiratory unit, contains between 3 to 5 terminal bronchioles, alveolar ducts and alveoli. The alveoli are made of one layer of squamous epithelium surrounded by another layer of connective tissue along with numerous capillaries as shown in figure 2C. Type I and type II alveolar pneumocytes appeared normal (Figure 2D).

In group 3, the lung exhibited marked changes in the morphology after two-week exposure to tobacco smoke (Figure 3A-3D). The bronchiole's wall consists of normal ciliated cuboidal epithelium (Figure 3C). However, cellular hyperplasia, thickening in the alveolar wall, and infiltration of inflammatory cells were clearly evident (Figure 3D).

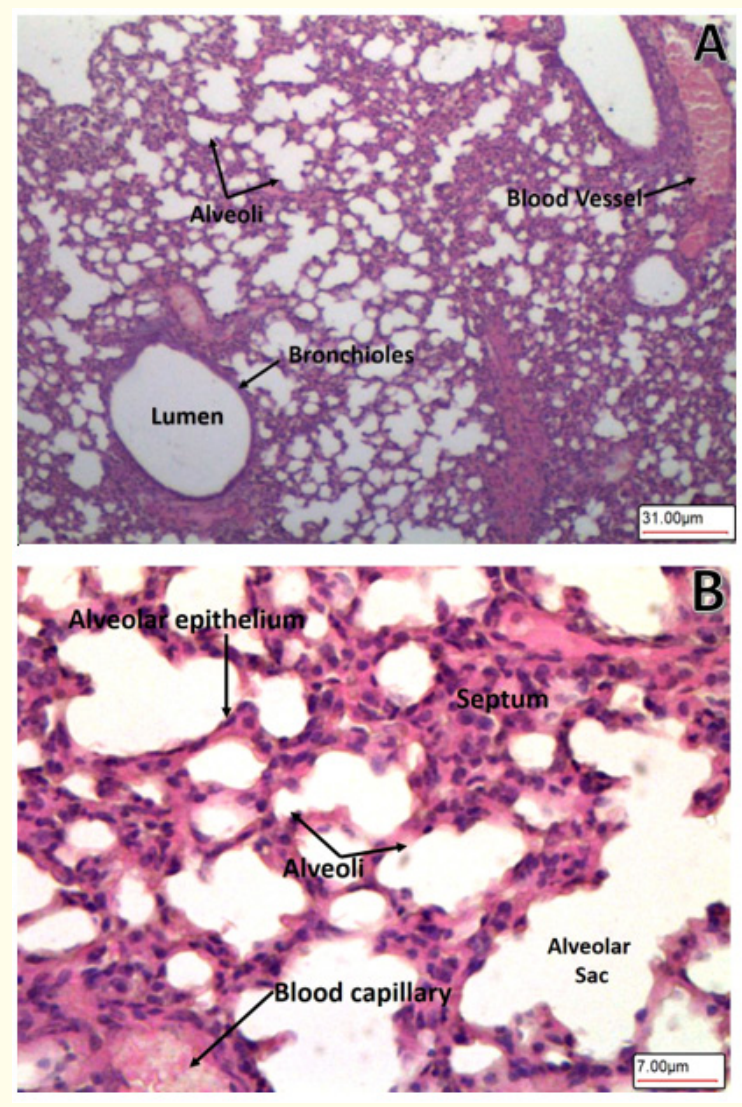




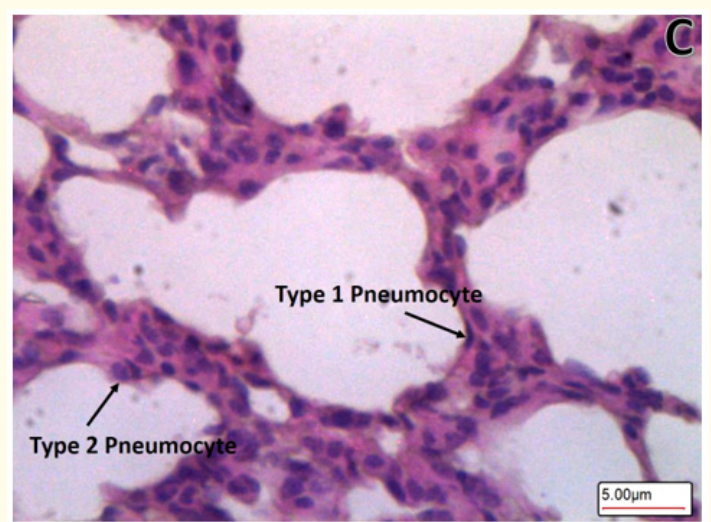

Figure 1: Light microscopy image of H\&E stained lung from the control group showing lung with bronchus bifurcate into narrower bronchi that terminate in bronchioles, alveolar ducts and alveoli. Blood vessels clearly represented in this tissue (A: Mag.100x). Alveoli s consists of alveolar septum, simple squamous epithelium and blood capillaries (B: Mag. 400x). Alveolar wall made of two morphologically distinct simple squamous cells type I and type II pneumocytes (C: Mag 600x).

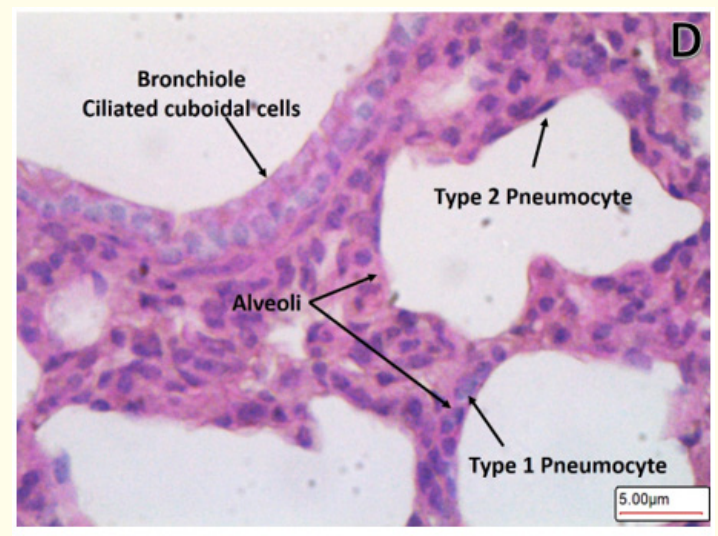

Figure 2: Microscopy image of H\&E stained lung from the tobacco smoke-exposed group two with normal lung bronchioles, alveolar ducts and alveoli, blood vessels clearly represented in this tissue (A: Mag. 100x.). Bronchiole consists of ciliated cuboidal epithelium (B: Mag 400x). Alveoli consists of simple squamous epithelium and blood capillaries (C: Mag 400x). Type I and type II pneumocytes and bronchiole ciliated cuboidal cells clearly visible (D: Mag 600x).
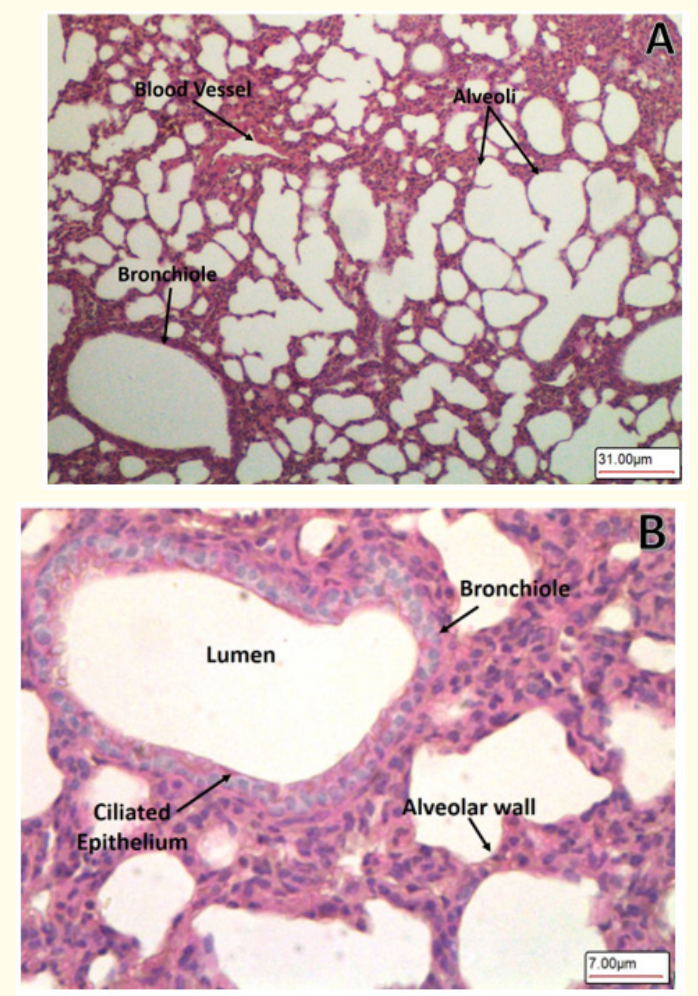
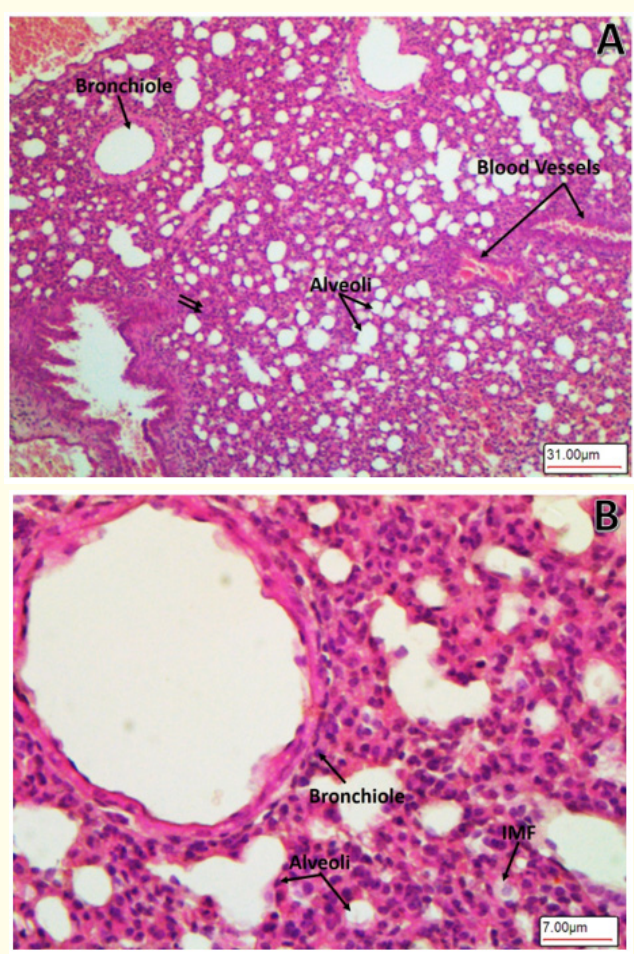

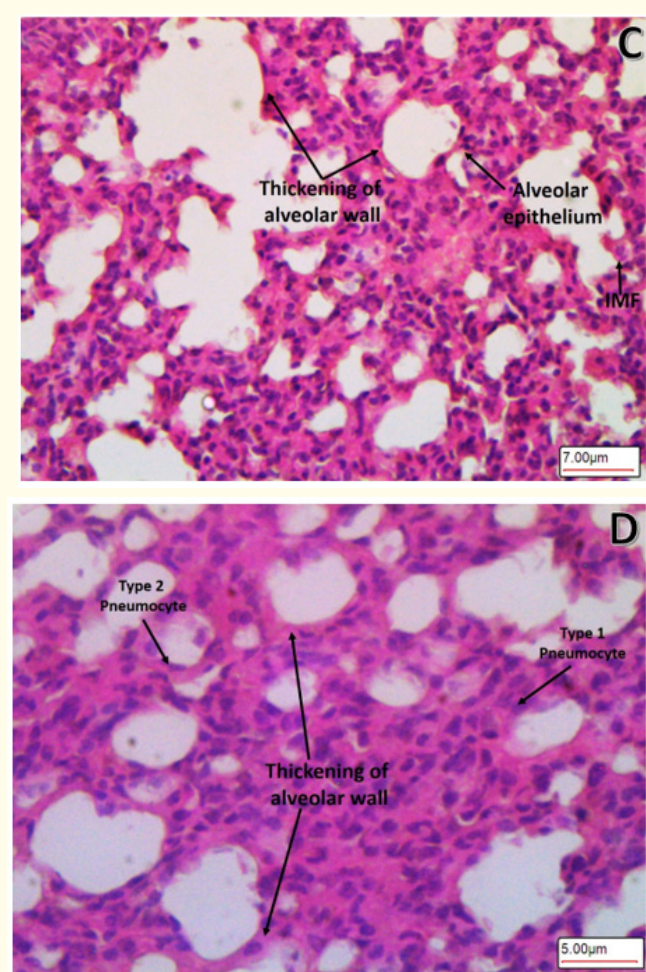

Figure 3: Light microscopy image of H\&E stained lung from the tobacco smoke exposed group three showing lung with bronchioles, alveolar ducts and alveoli, and blood vessels (Figure 3A-3D). Cellular hyperplasia was visible (double arrow) (A: Mag. 100x). Infiltration of inflammatory cells (IMF) (B: Mag 400x) and thickening in the alveolar wall was observed (C\&D: Mag 400x, 600x).

\section{Discussion}

The two to three-week exposure administrated in the current study was based on a similar model for mice that offers greater reproducibility in a reasonable time frame. Previous investigations of tobacco smoke-induced emphysema have administrated exposure periods of up to 36 weeks $[11,12]$. However, exposure to daily dose of tobacco smoke for 2 weeks caused a degree of thickening to the tissues of lungs obtained from the 10-day juvenile mice. Effect of prenatal tobacco smoke on the lung's tissues in the present study, cellular hyperplasia, and thickening in the alveolar that was detected within the lung epithelium was attributed to cell degeneration. These findings support other studies that found smoking may be the major factor behind the histopathological changes in the respiratory passages that affects the gaseous exchange and may predispose to cancerous changes [5]. Tobacco smoke, which is classified as one of the factors that lead to cancer in human, in linked to the major alterations of multigene expression in mice's lungs [13,14] and rats' lungs [15, 16]. Similarly, Ziad., et al. [17] found that lung alveoli of tobacco smoke exposed rats showed clear thickening in the alveolar wall tissue, collapsed alveoli, inflammatory cell infiltration and blood extravasations and concluded that hyperplasia of alveolar cells was a feature in the affected lung tissue. Similarly, D’Agostino., et al. [18] demonstrated that exposing mice to tobacco smoke is a strong inducer of apoptosis in pulmonary alveolar macrophages. Tobacco smokes might be the reason behind the detected lungs' cell proliferation, which is known to be stimulated in the respiratory tract of tobacco exposed mice with mechanisms involved in the carcinogenetic process were found to be affected in mice lungs [19]. These morphological developments were attributed to the amount of toxic substances in the prenatal tobacco smoke [20]. The alveolar cells thickening which is associated and directly linked to smoking, may greatly accelerating the tissue damage by inducing the formation of oxygen free radicals or through the secretion of lytic enzymes [5]. Epithelial cell injuries induced by the rat exposure to fumes caused an amplification in the occurrence of metaplasia [21]. The current histological observations were also reported by Tang., et al [22]. Oxidative lung injury and inflammation in response to tobacco smoke may speed up the functional and morphological changes and gradually limiting the gaseous exchange [23]. Tobacco smoke causes an aggregation of inflammatory cells in the lung tissue [17]. These inflammatory cells are considered as a possible factor that leads to the destruction of the alveolar and interstitial pulmonary morphologies through the accumulation of lytic enzymes and oxygen free radicals. Besides nicotine, tobacco smokes contain various carcinogen compounds which are formed during tobacco curing and burning $[22,24]$. During burning of tobacco, nicotine can be converted into nitrosamines [22]. Cigarette fumes also lead to an aggregation of inflammatory cells in the lung tissue. These inflammatory cells are attributed to the destruction of the alveolar and interstitial pulmonary structures through secretion of lytic enzymes and oxygen free radicals [5]. However, the timeframe of tobacco smoke exposure and the number of cigarettes consumed are the major factors in lung histomorphological changes.

\section{Conclusion}

Lung alveoli of prenatal tobacco smoke-exposed mice showed clear thickening in the alveolar wall tissue, aorta, collapsed alveoli, inflammatory cell infiltration, blood extravasations and all affects 
the gaseous exchange and may predispose to cancerous changes. Therefore, the results showed that tobacco exposure to pregnant female mice may affects lung development which in turn may cause lung diseases. Smoking induces histopathological changes in the respiratory passages and aorta that affects the gaseous exchange and may predispose to cancerous changes. Further investigation is recommended to increase the tobacco smoke exposure time to evaluate the extent of damage caused by nicotine. The current results simply suggest, on the basis of experimental data in model systems, that this issue warrants in-depth study in the future using electronic microscope.

\section{Declaration of Competing Interest}

The authors declare that they have no conflict of interest.

\section{Acknowledgment}

The DARIS Research Centre and Laboratory for Stem Cells and Regenerative Medicine at Natural and Medical Sciences Research Centre, University of Nizwa which provided the facilities to carry out the project is highly appreciated. This work was supported by a grant from the Research Council, Sultanate of Oman.

\section{Bibliography}

1. Benowitz NL. "Nicotine addiction". The New England Journal of Medicine 362 (2010): 2295-2303.

2. Hoffmann D and E Wynder. "Chemical constituents and bioactivity of tobacco smoke". International Agency for Research on Cancer 74 (1986): 145-165.

3. Stephen M. "The toxicological of cigarette smoke and environmental tobacco smoke". Rep Assign-Biochemical Toxicology (2010): BC4927.

4. Ding Y., et al. "Levels of tobacco-specific nitrosamines and polycyclic aromatic hydrocarbons in mainstream smoke from different tobacco varieties". Cancer Epidemiology, Biomarkers and Prevention 17 (2008): 3366-3371.

5. Shraideh Z., et al. "Effects of cigarette smoking on histology of trachea and lungs of albino rat". Research Opinions in Animal and Veterinary Sciences 3 (2013): 356-362.

6. Shraideh Z and H Najjar. "Histological changes in tissues of trachea and lung alveoli of Albino rats exposed to the smoke of two types of Narghile Tobacco Products". Jordanian Journal of Biological Science 4 (2011): 149-156.
7. Erzen I and LZ Kragelj. "Cadmium concentrations in blood in a group of male recruits in Slovenia related to smoking habits". Bulletin Environmental Contamination and Toxicology 76 (2006): 278-284.

8. Fuller BF., et al. "Effects of environmental tobacco smoke on adult rat brain biochemistry". Journal of Molecular Neuroscience 41 (2010): 165-171.

9. D'Agostino B., et al. "Mesenchymal stem cell therapy for the treatment of chronic obstructive pulmonary disease". Expert Opinion in Biological Therapy 10 (2010): 681-687.

10. Kozma RDH., et al. "A new experimental model of cigarette smoke-induced emphysema in Wistar rats". Journal of Brasilin Pneumology 40 (2014): 46-54.

11. Guerassimov A., et al. "The development of emphysema in cigarette smoke-exposed mice is strain dependent". American Journal of Respiratory and Critical Care Medicine 170 (2004): 974-980.

12. Marumo CK., et al. "Hemodynamic effects of PEEP in a porcine model of HCl-induced mild acute lung injury". Acta Anaesthesiological Scandinavica 53 (2009):190-202.

13. Izzotti A., et al. "Alterations of gene expression in skin and lung of mice exposed to light and cigarette smoke". FASEB Journal 18 (2004a): 1559-1561.

14. Izzotti A., et al. "Gene expression in the lung of p53 mutant mice exposed to cigarette smoke". Cancer Research 64 (2004b): 8566-8572.

15. Izzotti., et al. "Modulation of multigene expression and proteome profiles by chemo preventive agents". Mutation Research 591 (2005a): 212-223.

16. Izzotti A. "Chemoprevention of genome, transcriptome, and proteome alterations induced by cigarette smoke in rat lung". European Journal of Cancer 41 (2005b): 1864-1874.

17. Ziad S., et al. "Effects of cigarette smoking on histology of trachea and lungs of albino rat". Research Opinions in Animal and Veterinary Sciences 3 (2013): 356-362.

18. D’Agostino F., et al. "Modulation of apoptosis by chemo preventive agents". Mutilation Research 591 (2005): 173-186.

19. De Flora S., et al. "High susceptibility of neonatal mice to molecular, biochemical and cytogenetic alterations induced by environmental cigarette smoke and light". Mutation Research 659 (2008): 137-146. 
20. Kurus M., et al. "The effect of resveratrol in tracheal tissue of rats exposed to cigarette smoke". Inhalation Toxicology 21 (2009): 979-984.

21. Mikaili P., et al. "A histological study on the effects of aqueous extract of Althea officinalis on epithelial and submucosal mucocilliary system of rat trachea following inhalation of cigarette smoke". Iranian Journal of Pharmaceutical Research 3 (2004): 56-57.

22. Tang MS., et al. "Electronic-cigarette smoke induces lung adenocarcinoma and bladder urothelial hyperplasia in mice". Proceedings of the National Academy of Sciences of the United States of America 116 (2019): 21727-21731.

23. De Faria CA., et al. "Experimental basis and new insights for cell therapy in Chronic Obstructive Pulmonary Disease". Stem Cell Review 8 (2012): 1236-1244.

24. Lee HW., et al. "Tang MSE-cigarette smoke damages DNA and reduces repair activity in mouse lung, heart, and bladder as well as in human lung and bladder cells". Proceedings of the National Academy of Sciences of the United States of America 115 (2018): E1560-E1569.

\section{Assets from publication with us}

- Prompt Acknowledgement after receiving the article

- Thorough Double blinded peer review

- Rapid Publication

- Issue of Publication Certificate

- High visibility of your Published work

Website: www.actascientific.com/

Submit Article: www.actascientific.com/submission.php

Email us: editor@actascientific.com

Contact us: +919182824667

Citation: Issa S Al-Amri, Isam T Kadim., et al. "Effects of Prenatal Tobacco Smoke on Lungs Histo-Morphological Changes of CD-1 Mice at Embryo Developmental Stage”. Acta Scientific Veterinary Sciences 2.12 (2020): 02-08. 